\title{
Финансовый рычаг, доходность и отраслевая специфика: эмпирическое исследование сделок слияний и поглощений
}

\author{
Аглиарди Э. ${ }^{21}$, Лукьянова И. ${ }^{22}$ \\ Перевод Кокорева Д. ${ }^{23}$
}

В данной статье рассматривается влияние сделок слияний и поглощзений на уровень долговой нагрузки компании, взаимосвязь между долговой нагрузкой и возможностями роста и то, каким образом меняется поведение покупателей в зависимости от принадлежности компании к той или иной отрасли. Мы также исследовали то, как распределительные характеристики доходности (среднее, волатильность, асимметрия, коррелящия) влияют на слияния и наличие связи между методом оплаты сделок $u$ снижением риска. Мы обнаружили, что компаниям из высокотехнологичных отраслей $c$ более высокими возможностями роста свойственна пониженная долговая нагрузка. Отрасли с большими возможностями роста обладают в основном недостаточно высоким финансовым рычагом, в то время как отрасли с небольшими возможностями роста чересчур высоким. У большинства компаний в отрасли промышленных товаров $u$ финансовом секторе наблюдается рост волатильности доходности акций после слияния, сопровождающийся снижением асимметрии распределения доходностей. $B$ наукоемких отраслях, за исключением химической промышленности, наблюдается уменьшение как волатильности, так и асимметрии распределения доходности после слияния.

\section{JEL: G32}

Ключевые слова: слияния, долговая нагрузка, финансовый рычаг, возможности роста, распределительные характеристики доходности.

\section{1. Введение}

Данное исследование отвечает на следующие вопросы: увеличивают ли компании после слияний долговую нагрузку, например, за счет сокращения разрыва между фактическим и целевым уровнями финансового рычага, действительно ли при слиянии компаниям с высокими перспективами роста свойственны низкие показатели финансового рычага, а также мы выявляем зависимость поведения покупателей от принадлежности компании к той или иной отрасли. Мы также исследовали, как распределительные характеристики доходности (среднее, волатильность, асимметрия, корреляция) влияют на слияния, а также наличие связи между методом оплаты сделок и снижением риска.

Данная тема уже достаточно тщательно исследована (Kayhan, 2007; Gugler, 2002; Uysal, 2011; Harford, 2009). Авторы часто используют традиционный набор детерминант целевой долговой нагрузки, например отношение рыночной стоимости к балансовой (market-to-book ratio, далее - M/B), переменные для определения степени материальности активов, уникальности производимой продукции, рентабельности и размера капитала компании. Авторы отмечают сокращение дефицита заемных средств после закрытия сделок, подразумевая изменение структуры капитала. Также обнаружена явная зависимость между финансовой гибкостью и возможностями роста. В некоторых случаях отмечается, что решения о слияниях объясняются предпочтениями покупателя к использованию теории

\footnotetext{
${ }^{21}$ Профессор факультета экономики Университета Болоньи (University of Bologna), Италия.

${ }^{22}$ Аспирантка Колледжа Европы (Collège d’Europe), Брюгге, Бельгия.

${ }^{23}$ Аспирант факультета экономики НИУ ВШЭ, кафедра экономики и финансов фирмы; стажер-исследователь лаборатории корпоративных финансов.
} 
порядка финансирования, возможностями роста покупателя, а также предпочтениям в способе оплаты сделки (Martynova, 2009).

Наши гипотезы согласуются с существующими исследованиями по данной теме, но, хотя различные эффекты изменения долговой нагрузки компаний хорошо описаны в литературе, круг работ, описывающих то, как дефицит заемных средств влияет на решения о слияниях в различных отраслях, все еще ограничен. Более того, только начинают появляться исследования того, как распределительные характеристики доходности влияют на предсказуемость результатов слияний, есть ли зависимость между распределением доходности, переоценкой и возможностями роста, а также каким образом оказывает влияние метод оплаты сделки. Таким образом, наша статья продолжает указанные направления исследований, показывая на нашей выборке взаимосвязь между дефицитом заемных средств, возможностями роста и сокращением риска в различных отраслях при различных типах слияний.

Статья структурирована следующим образом. Во втором разделе обсуждается выборка и методология измерения долговой нагрузки (используются как рыночные показатели собственного капитала, так и балансовые), а также анализируются эмпирические данные в разрезе различных отраслей. Следуя Фама (Fama, 2002), мы разделили нашу выборку по отраслям в соответствии с четырехзначным кодом SIC, и в некоторых случаях скомбинировали отрасли в 9 отраслевых секторов (сырьевой, потребительские и промышленные товары, услуги, здравоохранение, финансовый сектор, технологии и энергоносители). В соответствии с теоретическими предпосылками, компании с более высокими возможностями роста, принадлежащие к высокотехнологичным отраслям, имеют более низкий уровень долговой нагрузки и показывают наименьшие значения финансового рычага, в то время как компании с низкой возможностью для развития в среднем перекредитованы. В частности, в фармацевтической отрасли и производстве электроники у компаний остаются возможности для увеличения долговой нагрузки даже после слияний, в то время как в таких отраслях, как пищевая, издательская, сырьевая, строительная, транспортная и производство промышленных товаров, наблюдается серьезный финансовый дефицит после слияний.

В части 3 представлен анализ взаимосвязи доходности акций компании и выгод от слияний в различных отраслях. Комбинируя данные по SIC-кодам и корреляции доходностей при слияниях, мы пытались определить различия между слияниями, осуществленными между компаниями из одной отрасли, и слияниями, совершенными с целью диверсификации, а также изучили изменение волатильности и асимметрии доходности после слияний. Большинство компаний в финансовом и сырьевом секторах показали увеличение показателя волатильности при уменьшении асимметрии. В сервисной и технологической отраслях оба параметра возрастают при закрытии сделок. Интересным является тот факт, что в наукоемких отраслях, за исключением химической отрасли, в среднем сокращается и волатильность, и асимметрия. Данные результаты интерпретируются совместно с анализом методов оплаты и различных типов слияний. В 4-й главе мы подводим итоги исследования.

\section{2. Методология исследования и обсуждение результатов}

\section{1. Выборка и процедуры оценки: изменение финансового рычага}

Мы используем данные из трех разных баз данных. Данные о слияниях, совершенных в период с 1977 по 2010 год, взяты и базы данных Thomson Reuters SDC Platinum. Выборка включает данные о слияниях американских компаний (за исключением сделок LBO, обратного выкупа, рекапитализации, а также сделок в энергетической отрасли и отрасли ЖКХ, а также сделок с размером более 100 млн долларов). Все сделки - дружественные слияния, с одним покупателем, сделавшим предложение. Данные о структуре капитала всех компаний, попавших в выборку за год до слияния и год после сделки, брались из базы 
данных Compustat. В итоге выборка включает в себя 562 наблюдения. Используя методологию Южела (Uysal, 2011), мы применяем регрессионный анализ с учетом фиксированных эффектов для определения оптимального уровня финансового рычага. Для отслеживания эффектов изменения рыночной стоимости компании мы используем рыночные показатели долговой нагрузки как зависимую переменную, которая определяется как отношение балансовой стоимости долга к рыночной стоимости компании (далее могут использоваться понятия «рыночный долг» или «рыночный финансовый рычаг»). Целевой уровень долга оценивается для следующих периодов: в год завершения слияния, в следующем после завершения слияния году, а для поглощенных компаний - за год, предшествующий поглощению с целью отслеживания изменений целевой структуры капитала и дефицита в заемных средствах. При этом дефицит заемных средств определяется как действующая долговая нагрузка компании за вычетом оптимальной долговой нагрузки, определенной с помощью регрессионного анализа.

Затем мы построили аналогичные регрессионные модели, но уже используя балансовые значения долговой нагрузки (балансовая стоимость долга к совокупным активам компании, далее - балансовый уровень долга или балансовый финансовый рычаг) как зависимую переменную вместо рыночных показателей, и сравнили полученные результаты. Данное сравнение, достаточно новое в академических исследованиях ${ }^{24}$, позволяет провести анализ эффекта некорректности рыночной стоимости компании (Rhodes-Kropf, 2004), что зачастую считается ключевым мотивом для осуществления слияний и поглощений. Фактически мы наблюдаем рост активности слияний и поглощений тогда, когда рынок переоценивает компании-покупателей, что повышает для данных компаний стимулы к приобретению недооцененных компаний. Хотя далее мы также обсудим случаи, когда переоцененные покупатели приобретают те компании, которые работают в менее переоцененных отраслях, чем отрасль покупателя.

Продолжая предыдущие исследования структуры капитала, такие как (Kayhan, 2007; Uysal, 2011; Yang, 2009), мы включаем семь объясняющих переменных в регрессии при определении целевой структуры капитала: EBITDA, M/B, R\&D, DR\&D, PPE, SEXP, SIZE (переменные более подробно описаны далее). Bce переменные (за исключением рентабельности) лагированы на один период назад с целью снижения вероятности проявления эндогенности.

Переменная EBITDA (EBITDA/общие активы): следуя методологии Харфорд (Harford, 2009), мы используем прогнозные значения рентабельности ${ }^{25}$ компании (определяемой как прибыль до уплаты процентов, налогов, амортизации материальных и нематериальных активов, разделенная на совокупную величину активов компании), так как статические компромиссные теории выбора структуры капитала показывают, что при сравнении преимуществ налогового щита и издержек финансовой неустойчивости фирмы с более высоким уровнем рентабельности имеют повышенную долговую нагрузку.

Существуют аргументы в поддержку как положительной, так и отрицательной взаимосвязи рентабельности и долговой нагрузки. С одной стороны, более прибыльные компании должны иметь меньший риск дефолта и получать больше преимуществ от

\footnotetext{
24 Исследование, проведенное в бизнес-школе Stern университета Нью-Йорка (NYU), 2010, в котором сравнивается отношение рыночной и балансовой стоимостей 3500 американских компаний за 20-летний период, показывает существенное сниженные значимости материальных активов компании (с соответствующим ростом стоимости нематериальных активов). Как сказал Бэн Макларе: «В 1978 году рыночные и балансовые стоимости компаний соответствовали друг другу: балансовая стоимость компании составляла до 95\% ее рыночной стоимости. Спустя 20 лет балансовая стоимость составляет только около 28\% рыночной стоимости компании».

${ }^{25}$ Если мы строим регрессии, в которых текущий уровень долговой нагрузки зависит от предыдущего уровня рентабельности, тогда ожидаемый коэффициент будет содержать в себе влияние неожидаемой рентабельности на долговую нагрузку, что может вызвать проблемы при интерпретации результатов изменения структуры капитала покупателя. Использование ожидаемого уровня рентабельности позволяет нам избежать проблем подобного рода.
} 
использования налогового щита, что приводит к положительной взаимосвязи между уровнем рентабельности и долговой нагрузкой. Также, как было отмечено Дженсен (Jensen, 1986), положительная взаимосвязь между рентабельностью и уровнем долговой нагрузки отражает в себе снижение инициативы менеджмента по использованию свободных денежных потоков для осуществления излишних инвестиций. С другой стороны, рентабельность - индикатор рыночной власти, что подразумевает отрицательную зависимость между рентабельностью и долгом (Kayhan, 2007). Уровень рентабельности выше среднего является индикатором пониженной конкуренции в отрасли, что позволяет более прибыльным компаниям избегать высокой долговой нагрузки, которая могла бы использоваться для предотвращения рыночных угроз, например выведения на рынок новых продуктов конкурентов или другого рода агрессивного поведения игроков отрасли.

Также для прибыльных компаний издержки приспособления уровня долга иногда могут быть выше, нежели издержки от поддержания структуры капитала близкой к оптимальному уровню, что приводит к пониженным уровням долговой нагрузки. В дополнение теория порядка финансирования предполагает, что компании предпочитают внутренние источники фондирования внешним, что приводит к пониженной долговой нагрузке более прибыльных компаний. Большинство существующих исследований подтверждают значимость издержек приспособления, что указывает на отрицательную зависимость долговой нагрузки от рентабельности.

Переменная M/B (отношение рыночной стоимости активов к балансовой). Данный показатель наряду с Q-Тобина широко используется для определения возможностей роста компании. Более высокий показатель М/В означает большие возможности роста для компании. Как отмечает Майерс (Myers, 1977), существенная долговая нагрузка и высокий уровень недоинвестирования наблюдается в растущих компаниях. Каи (Саi, 2011) в своей статье показал, что увеличение долговой нагрузки ассоциируется со снижением объемов роста инвестиций в будущем. В целом исследователи единодушны в вопросе негативной зависимости рыночного уровня долговой нагрузки от показателя М/В. Хотя, несмотря на эмпирические доказательства отрицательной зависимости балансового уровня долга и возможностей роста, Барклай и Харфорд (Barclay, 2006; Harford, 2010) в своих работах показали положительную взаимосвязь между этими величинами. Также дополнительные подтверждения того, что между балансовым уровнем долга и показателем М/В существует положительная взаимосвязь, отмечаются в работах Фама и Фрэнк (Fama, 2002; Frank, 2010). Харфорд (Harford, 2010) показал, что в случае отсутствия агентского конфликта между акционерами и кредиторами взаимосвязь между уровнем долга и показателем М/В можно описать кривой U-образной формы. Они отмечают важность своих результатов, так как в литературе отрицательная зависимость между рыночным (а также и балансовым) уровнем долга и Q-Тобина объясняется агентскими издержками долга. Тот факт, что рыночный уровень долга сначала сокращается, а затем начинает возрастать (с ростом Q-Тобина), может быть объяснен следующим образом: в случае незначительного влияния возможностей роста на стоимость компании увеличение Q-Тобина оказывает незначительный эффект на объем платежей по обслуживанию долга, следовательно, рыночный объем долга сокращается с ростом Q-Тобина. Но после определенной точки возможности роста для компании приобретают существенную значимость, что при дальнейшем росте показателя М/B ведет к росту процентных платежей и к увеличению уровня долга.

Переменная R\&D (расходы на НИОКР по отношению к объему продаж - оба показателя за год, предшествующий слиянию). Считается, что повышенные затраты на НИОКР обеспечивают больше возможностей для роста и увеличивают долю стоимости компании, составляемую нематериальными активами, которые сложно использовать в качестве залогов. В результате компании, которые вкладывают средства в НИОКР, предположительно, имеют меньшую долговую нагрузку. В дополнение активное вложение в НИОКР приводит к производству уникальных или специализированных товаров, которые сложно будет заменить, в случае если компания прекратит свою деятельность. Уникальность 
производимой продукции увеличивает издержки банкротства, снижая, таким образом, целевой уровень финансового рычага. То есть узкая специализация компании и производство уникальных товаров, как ожидается, окажут отрицательное воздействие на уровень долга.

При этом данные для переменной НИОКР были найдены не для всех наблюдений. Таким образом, мы ввели дамми-переменную для дифференциации таких наблюдений.

Переменная РРЕ (долгосрочные материальные активы предприятия по отношению к совокупным активам предприятия - оба показателя за год, предшествующий слиянию). Величина материальных активов может быть использована как переменная для определения залоговой массы, что означает увеличение возможностей для привлечения заемных средств у компаний с большей величиной активов. Компаниям с ликвидными активами присущи меньшие издержки финансовой неустойчивости, что ведет к большей долговой нагрузке.

Переменная SEXP (расходы на осуществление продаж к общему объему продаж - оба показателя за год, предшествующий слиянию). Аналогично расходам на НИОКР увеличение расходов на продвижение продукции позволяет компании производить более специализированную продукцию. Таким образом, ожидается отрицательное воздействие данных затрат на уровень долга компании.

Переменная SIZE (натуральный логарифм продаж за год, предшествующий слиянию). Данный показатель используется как переменная для определения размера компании и, вероятнее всего, положительно связана с объемом долга. Как правило, больший уровень продаж и больший размер компании позволяют компании занимать больше заемных средств из-за более легкого доступа к рынкам капитала и большей диверсификации.

Результаты наших регрессий представлены в таблицах 1, 2 и 3. Важно отметить существенное различие результатов при использовании рыночного и балансового уровней долга. Например, при скорректированном R-квадрат прогноз целевого уровня рыночного долга в момент слияния значительно выше, чем аналогичный балансовый показатель. Все объясняющие переменные значимы на 1\%-ном уровне значимости и имеют ожидаемые направления воздействия, за исключением переменной $\mathrm{R} \& \mathrm{D}$, которая на 5\%-ном уровне значимости имеет положительную взаимосвязь с рыночным уровнем долга. Регрессии на определение целевого уровня балансового долга показали плохие результаты: значимыми на 5\%-ном уровне значимости оказались только две переменные - рентабельность и структура активов.

Таблица 1

Ожидаемая величина финансового рычага в момент слияния

\begin{tabular}{|c|c|c|c|}
\hline \multicolumn{2}{|c|}{$\begin{array}{c}\text { Финансовый рычаг на основе рыночных } \\
\text { показателей }\end{array}$} & \multicolumn{2}{|c|}{$\begin{array}{c}\text { Финансовый рычаг на основе } \\
\text { балансовых показателей }\end{array}$} \\
\hline Переменная & Коэффициент & Переменная & Коэффициент \\
\hline EBITDAt +1 & $\begin{array}{l}-0,335247 * * * \\
(5,47)\end{array}$ & EBITDAt+1 & $\begin{array}{l}0,237718^{* *} \\
(2,45)\end{array}$ \\
\hline $\mathrm{M} / \mathrm{Bt}-1$ & $\begin{array}{c}-0,015931 * * * \\
(-8,36)\end{array}$ & $\mathrm{M} / \mathrm{Bt}-1$ & $\begin{array}{c}-0,002867 \\
(-1,03)\end{array}$ \\
\hline PPEt-1 & $\begin{array}{c}0,115378^{* * *} \\
(3,15)\end{array}$ & PPEt-1 & $\begin{array}{l}0,098711^{* *} \\
\quad(2,11)\end{array}$ \\
\hline R\&Dt-1 & $\begin{array}{l}0,283253^{* *} \\
(2,54)\end{array}$ & R\&Dt-1 & $\begin{array}{c}-0,162661 \\
(-0,93)\end{array}$ \\
\hline DR_Dt-1 & $\begin{array}{l}-0,008065 \\
(-0,51)\end{array}$ & DR_Dt-1 & $\begin{array}{c}0,028255 \\
(1,21)\end{array}$ \\
\hline SEXPt-1 & $\begin{array}{c}-0,157788 * * * \\
(-5,42)\end{array}$ & SEXPt-1 & $\begin{array}{c}0,003877 \\
(0,09)\end{array}$ \\
\hline SIZEt-1 & $\begin{array}{l}0,007927^{*} \\
(1,77)\end{array}$ & SIZEt-1 & $\begin{array}{c}0,008460 \\
(1,53)\end{array}$ \\
\hline Constant & $0,351084 * * *$ & Constant & $0,342924 * * *$ \\
\hline
\end{tabular}




\begin{tabular}{lccc|}
\hline & $(8,76)$ & & $(6,50)$ \\
Adjusted R-squared & 0,33 & Adjusted R-squared & 0,10 \\
\hline В скобках указана & $t$-статистика; $* * *, * *$ и $*$ показывают уровени значимости $-1,5$ и \\
$10 \%$ соответственно. &
\end{tabular}

Таблица 2

Ожидаемая величина финансового рычага до слияния

\begin{tabular}{|c|c|c|c|}
\hline \multicolumn{2}{|c|}{$\begin{array}{c}\text { Финансовый рычаг на основе рыночных } \\
\text { показателей }\end{array}$} & \multicolumn{2}{|c|}{$\begin{array}{c}\text { Финансовый рычаг на основе } \\
\text { балансовых показателей }\end{array}$} \\
\hline Переменная & Коэффициент & Переменная & Коэффициент \\
\hline EBITDAt & $\begin{array}{c}-0,371991 * * * \\
(-7,064618)\end{array}$ & EBITDAt & $\begin{array}{c}-0,058710 \\
(-0,644005)\end{array}$ \\
\hline $\mathrm{M} / \mathrm{Bt}-2$ & $\begin{array}{c}-0,015692 * * * \\
(-8,524151)\end{array}$ & $\mathrm{M} / \mathrm{Bt}-2$ & $\begin{array}{c}-0,004085^{* * *} \\
(-2,706206)\end{array}$ \\
\hline PPEt-2 & $\begin{array}{r}0,063100^{* *} \\
(2,101218)\end{array}$ & PPEt-2 & $\begin{array}{r}0,105823 * * \\
(2,276420)\end{array}$ \\
\hline R\&Dt-2 & $\begin{array}{c}0,275561 * * * \\
(3,218635)\end{array}$ & R\&Dt-2 & $\begin{array}{c}0,310866 * * * \\
(2,947180)\end{array}$ \\
\hline DR\&Dt-2 & $\begin{array}{c}0,017405 \\
(1,417802)\end{array}$ & DR_Dt-2 & $\begin{array}{r}-0,044151^{* *} \\
(-2,416805)\end{array}$ \\
\hline SEXPt-2 & $\begin{array}{r}0,153736^{* * *} \\
(-5,491162)\end{array}$ & SEXPt-2 & $\begin{array}{c}-0,073629 \\
(-1,534423)\end{array}$ \\
\hline SIZEt-2 & $\begin{array}{c}0,020978 * * * \\
(5,925731)\end{array}$ & SIZEt-2 & $\begin{array}{c}-0,073629 \\
(4,572677)\end{array}$ \\
\hline Constant & $\begin{array}{c}0,216941 * * * \\
(6,709237)\end{array}$ & Constant & $\begin{array}{c}0,309375 * * * \\
(5,724989)\end{array}$ \\
\hline Adjusted R-squared & 0,36 & Adjusted R-squared & 0,27 \\
\hline
\end{tabular}

Таблица 3

Ожидаемая величина финансового рычага после слияния

\begin{tabular}{|c|c|c|c|}
\hline \multicolumn{2}{|c|}{$\begin{array}{c}\text { Финансовый рычаг на основе рыночных } \\
\text { показателей }\end{array}$} & \multicolumn{2}{|c|}{$\begin{array}{c}\text { Финансовый рычаг на основе } \\
\text { балансовых показателей } \\
\end{array}$} \\
\hline Переменная & Коэффициент & Переменная & Коэффициент \\
\hline EBITDAt +2 & $\begin{array}{c}-0,531358 * * * \\
(-6,552925)\end{array}$ & EBITDAt+2 & $\begin{array}{c}-0,062112 \\
(-1,044324)\end{array}$ \\
\hline $\mathrm{M} / \mathrm{Bt}$ & $\begin{array}{l}-0,005957 * * * \\
(-4,557761)\end{array}$ & $\mathrm{M} / \mathrm{Bt}$ & $\begin{array}{l}-0,000106 \\
(-0,044532)\end{array}$ \\
\hline PPEt & $\begin{array}{r}0,101519 * * \\
(2,395501)\end{array}$ & PPEt & $\begin{array}{c}0,005138 \\
(0,163087)\end{array}$ \\
\hline $\mathrm{R} \& \mathrm{Dt}$ & $\begin{array}{c}0,335637 * * * \\
(3,558088)\end{array}$ & $\mathrm{R} \& \mathrm{Dt}$ & $\begin{array}{l}0,185603^{*} \\
(1,892089)\end{array}$ \\
\hline DR_Dt & $\begin{array}{l}-0,003321 \\
(-0,205510)\end{array}$ & DR_Dt & $\begin{array}{c}0,023794 \\
(1,520775)\end{array}$ \\
\hline SEXPt & $\begin{array}{c}-0,204565^{* * *} \\
(-4,7201)\end{array}$ & SEXPt & $\begin{array}{l}-0,016959 \\
(-0,519453)\end{array}$ \\
\hline SIZEt & $\begin{array}{c}0,012318^{* *} \\
(2,362190)\end{array}$ & SIZEt & $\begin{array}{c}0,010392 * * * \\
(2,839256)\end{array}$ \\
\hline Constant & $0,365234 * * *$ & Constant & $0,373456 * * *$ \\
\hline
\end{tabular}


Adjusted R-squared

В скобках указана $t$-статистика. ${ }^{* * *},{ }^{*}$ и ${ }^{*}$ показывают уровени значимости $-1,5$ и $10 \%$ соответственно.

Крупные компании и фирмы с большим объемом материальных активов имеют более высокие уровни целевого уровня долга, в то время как увеличение рентабельности и уникальности производимой продукции сокращает долю заемных средств. Так, из таблицы 1 следует, что показатель М/В и объем материальных активов являются одними из наиболее значимых переменных в объяснении целевого уровня долга. Но это не так при предсказании целевого уровня долга на основе балансовых показателей. Так, в работе Ву $(\mathrm{Wu}, 2010)$ рассматривается постоянство компании в выборе уровня долговой нагрузки: в среднем уровень долговой нагрузки (независимо от способа измерения: рыночный или балансовый) при росте компании остается постоянным. Для подтверждения данной идеи они тестируют долгосрочную объясняющую силу первоначальных показателей $\mathrm{M} / \mathrm{B}$ и материальности активов, контролируя при этом те детерминанты структуры капитала, которые широко используются в литературе (Bradley, 1984; Titman, 1988; Rajan, 1995; Fama, 2002): рентабельность активов компании, М/В и материальность активов, размер и отраслевая принадлежностькомпании, дивиденды и т.п.

Они показали, что и первоначальные показатели М/В и материальности активов являются объясняющими переменными целевой структуры капитала на протяжении 20 лет. При этом если степень материальности активов существенно меняется с годами, первоначальный показатель М/B все еще сохраняет свою объясняющую силу. Данное наблюдение особенно важно, так как показатель Q-Тобина является прокси-переменной как для возможностей роста, так и для оценки настроений рынка, что ведет к противоречивой интерпретации в исследованиях. Данный результат показывает, что первоначальный уровень М/В может объяснять текущую структуру капитала, делая малоприменимыми механизмы, основанные на отслеживании рынка.

Таблицы 4 и 5 суммируют информацию об отношении компании к текущему уровню долга и изменению дефицита заемных средств. Они выглядят более согласованными с ожидаемыми результатами, если мы будем прогнозировать балансовый уровень долговой нагрузки, а не рыночный.

Таблица 4

Описательная статистика дефицита в заемных средствах приобретаемых компаний

(на основе рыночного уровня долга)

\begin{tabular}{|lllll|}
\hline \multicolumn{1}{|c}{ Переменная } & $\begin{array}{l}\text { Количество } \\
\text { наблюдений }\end{array}$ & \multicolumn{1}{c}{ Средняя } & \multicolumn{1}{c|}{ Медиана } & \multicolumn{1}{c|}{$\begin{array}{c}\text { Стандартное } \\
\text { отклонение }\end{array}$} \\
\hline $\begin{array}{l}\text { Финансовый рычаг } t \\
\text { Дефицит заемных }\end{array}$ & 562 & 0,2948 & 0,2740 & 0,1910 \\
$\begin{array}{l}\text { средств } t-1 \\
\text { Дефицит заемных }\end{array}$ & 562 & $-0,0055$ & $-0,0326$ & 0,1301 \\
$\begin{array}{l}\text { средств } t \\
\text { Дефицит заемных } \\
\text { средств } t+1\end{array}$ & 562 & $-0,0094$ & $-0,0435$ & 0,1558 \\
$\begin{array}{l}\text { Изменение текущего } \\
\text { финансового рычага } t-1\end{array}$ & 562 & $-0,0179$ & $-0,0509$ & 0,1795 \\
$\begin{array}{l}\text { Изменение текущего } \\
\text { финансового рычага } t\end{array}$ & 562 & $-0,0070$ & $-0,0065$ & 0,0970 \\
$\begin{array}{l}\text { Изменение текущего } \\
\text { финансового рычага } t+1\end{array}$ & 562 & 0,0464 & 0,0209 & 0,1160 \\
Изменение целевого & 562 & 0,0255 & 0,0132 & 0,1101 \\
\hline
\end{tabular}


финансового рычага $t$

Изменение целевого

562

0,0322

0,0295

0,0603

финансового рычага $t+1$

Таблица 5

Описательная статистика дефицита в заемных средствах приобретаемых компаний (на основе балансового уровня долга)

\begin{tabular}{|lllll|}
\hline \multicolumn{1}{|c}{ Переменная } & $\begin{array}{l}\text { Количество } \\
\text { наблюдений }\end{array}$ & \multicolumn{1}{c}{ Средняя } & \multicolumn{1}{c|}{ Медиана } & \multicolumn{1}{c|}{$\begin{array}{c}\text { Стандартное } \\
\text { отклонение }\end{array}$} \\
\hline $\begin{array}{l}\text { Финансовый рычаг } t \\
\text { Дефицит заемных }\end{array}$ & 562 & 0,465 & 0,475 & 0,200 \\
$\begin{array}{l}\text { средств } t-1 \\
\text { Дефицит заемных }\end{array}$ & 562 & $-0,040$ & $-0,046$ & 0,196 \\
$\begin{array}{l}\text { средств } t \\
\text { Дефицит заемных } \\
\text { средств } t+1\end{array}$ & 562 & $-0,001$ & $-0,001$ & 0,193 \\
$\begin{array}{l}\text { Изменение текущего } \\
\text { финансового рычага } t-1\end{array}$ & 562 & 0,037 & 0,042 & 0,202 \\
$\begin{array}{l}\text { Изменение текущего } \\
\text { финансового рычага } t\end{array}$ & 562 & $-0,006$ & 0 & 0,237 \\
$\begin{array}{l}\text { Изменение текущего } \\
\text { финансового рычага } t+1\end{array}$ & 562 & 0,022 & 0,011 & 0,100 \\
$\begin{array}{l}\text { Изменение целевого } \\
\text { финансового рычага } t\end{array}$ & 562 & 0,017 & 0,005 & 0,100 \\
$\begin{array}{l}\text { Изменение целевого } \\
\text { финансового рычага } t+1\end{array}$ & 562 & $-0,017$ & $-0,027$ & 0,060 \\
\hline
\end{tabular}

Финансовый рычаг (на основе рыночных показателей) на момент слияния, имеет среднее значение 0,295 и довольно высокий уровень стандартного отклонения - 0,191. Средний уровень дефицита заемных средств отрицателен до, во время, и после слияния, что может означать неоцененность компании (с целевым уровнем финансового рычага, превосходящим действующие значения). Более того, дефицит заемных средств повышен до и после слияний, что происходит из-за корректировки целевого уровня долга. Если быть точнее, то в нашей выборке компании увеличивают рыночный уровень долга на момент слияния и после него (на 4,6 и 2,6\% соответственно), что согласовывается с результатами предыдущих исследований, но при этом компании также активно увеличивают и целевые показатели финансового рычага (на 5 и 3,2\%), и, таким образом, увеличение целевого уровня долга более существенное, чем его фактическое увеличение. Южел (Uysal, 2011) утверждает, что целевой уровень долга может оказывать влияние на принятие решение о слиянии. При прочих равных условиях увеличение целевого уровня заемных средств создает риски финансовой нестабильности. Таким образом, увеличение целевого уровня долга может создавать возможности для поглощения компании. Но мы обнаружили отрицательное воздействие целевого уровня долга (на основе балансовых показателей) и дефицита заемных средств на решение о поглощении (так же как в работе Каихан (Kayhan, 2007), где отмечается, что компании очень чувствительны к изменению целевого уровня долга).

Как было отмечено в исследовании Дэнис (Denis, 2009), мотивом для существенных заимствований зачастую является потребность в средствах для ведения операционной деятельности компании, а не осуществление выплаты свободных денежных средств акционерам. Авторы исследования обнаружили, что существенное уменьшение уровня долга не осуществляется мгновенно, так же как мгновенно не наблюдаются результаты попыток изменить структуру капитала компании для приближения к долгосрочным целевым уровням. Их заключение согласуется с теорией структуры капитала, в рамках которой финансовая 
гибкость, выраженная в неиспользованной возможности увеличения долга, играет существенную роль в определении структуры капитала. Финансовый дефицит, следующий за значительным увеличением объема долга, преимущественно закрывается последующими заимствованиями. Таким образом, наблюдаемая динамика в уровне долговой нагрузки отражает инвестиционные возможности компании и реализацию денежных потоков, а не следует традиционным теориям порядка финансирования и компромиссной теории. Наши наблюдения относительно целевого рыночного уровня долга частично совпадают с компромиссной теорией, согласно которой увеличение уровня долговой нагрузки отражает движение к целевому (возможно, новому) уровню долга. По нашим оценкам, как фактический, так и целевой уровни долга двигаются однонаправленно при сохранении дефицита заемных средств, то есть неиспользованных возможностей для привлечения кредитов и займов.

Как обсуждалось в статье Де Анджело и соавторов (DeAngelo et al., 2011), использование возобновляемых источников заимствования, которые могут быть легко привлечены в любой момент (например, кредитных линий или размещения краткосрочных ценных бумаг) предполагает, что компании выстраивают свою структуру капитала таким образом, что всегда есть дополнительный долговой потенциал, который может быть использован позднее в случае потребности в привлечении дополнительных средств. Данный неиспользуемый долговой потенциал увеличивает финансовую гибкость компании, в отличие от случаев, когда денежные средства просто лежат на счетах. В любой момент времени уровень долговой нагрузки состоит из двух компонентов: постоянной долговой нагрузки и невыбранных лимитов.

Если говорить о целевом уровне заемного капитала (на основе балансовых показателей) мы наблюдаем несколько иную картину. Средний целевой уровень составляет около 46\%, со стандартным отклонением 20\%. За год до поглощения покупатели недокредитованы (финансовый дефицит в среднем составляет -0,04), что согласуется с результатами Южэл (Uysal, 2011). Мореллес (Morellec, 2008) предполагает, что будущие возможности для осуществления слияний оказывают воздействие на решения о структуре капитала. Например, более высокая вероятность слияний заставляет компании изначально сокращать дефицит заемных средств. Непосредственно перед слиянием компания, осуществляющая поглощение, достигает целевого уровня долга за счет увеличения текущего балансового уровня долга, таким образом, сокращая разрыв между текущим и целевым уровнями долга практически до нуля. После осуществления поглощения компании значительно увеличивают балансовый уровень долга, достигая положительного дефицита заемных средств (в среднем 0,037). Фактически балансовый уровень долга возрастает во время и после слияния, при сокращении целевого уровня. Данные выводы совпадают с предыдущими исследованиями отклонений от целевой структуры капитала. В конце концов, столь значительные расхождения двух величин объема долга (с использованием рыночных и балансовых показателей) могут объясняться некорректной оценкой стоимости компании рынком.

Некорректная оценка объясняется в работе Родес-Кропф (Rhodes-Kropf, 2005), в которой авторы пытались разложить показатель М/В на два компонента: отношение рыночной стоимости компании к истинной стоимости (таким образом, измеряя расхождение между рыночной и реальной стоимостью) и отношение истинной стоимости к балансовой (своего рода показатель возможностей роста компании). Они используют модель, которая связывает рыночную и балансовую стоимость капитала, чистую прибыль и долговую нагрузку. При расчете долга авторы учитывают то, что стоимость капитала у компаний с долговой нагрузкой, отличной от среднеотраслевой, также различается. В ряде отраслей существенная долговая нагрузка считается нормой, в то время как в других структура капитала компаний включает в сябя в основном акционерный капитал. Также авторы предполагают, что слияние более вероятно тогда, когда рыночная стоимость компании превышает истинную стоимость. Традиционная компромиссная теория предполагает постоянный уровень долга и, таким образом, процикличные балансовые показатели долговой 
нагрузки (предполагая, что балансовая стоимость активов менее зависима от экономической ситуации, чем рыночная).

Но, как мы можем наблюдать на примере нашей выборки, изменение целевой рыночной структуры капитала существенно выше, чем изменение целевой балансовой структуры капитала, при этом изменения происходят разнонаправленно. Данное наблюдение расходится с результатами работы Халлинг (Halling, 2011), согласно которым рыночная и балансовая долговая нагрузка компании изменяется однонаправленно. Из таблиц 4 и 5 мы видим, что рыночные и балансовые уровни долговой нагрузки снижаются за год до слияния. Это - типичное поведение для фирм, которые собираются осуществлять крупные инвестиции и/или планируют приобретения, поскольку они должны сохранить финансовую гибкость для осуществления дальнейших инвестиций. Однако долговая нагрузка увеличивается после слияний. Эти результаты обычно отмечаются и в других исследованиях. Например, Гхош (Ghosh, 2000) также отмечает существенное увеличение долговой нагрузки компании после слияния. В работе тестируется две гипотезы относительно причин такого увеличения. Во-первых, рост кредитоемкости объединенной компании (по сравнению с кредитоемкостью покупателя и продавца по отдельности) в результате сокращения волатильности доходов объединенной компании, более низкого риска и снижения издержек финансовой неустойчивости. Авторы указывают, что размер компании является важной детерминантой кредитоемкости, указывая, что у более крупных компаний, вероятно, будет более высокий оптимальный уровень долговой нагрузки вследствие более низкого риска неплатежа. Во-вторых, увеличение долговой нагрузки могло быть результатом использования свободной кредитоемкости компании цели, покупателя или обеих компаний. Их окончательные результаты подтверждают увеличение долговой нагрузки, а не кредитоемкости.

\section{2. Финансовый рычаг, возможности роста и отраслевые особенности}

Следуя методологии Фама (Fama, 2002), мы делим выборку по отраслям опираясь на четырехзначные SIC-коды, группируя отрасли в восемь категорий (сырьевая, товары народного потребления и промышленные товары, услуги, здравоохранение, финансовая, коммунальные услуги и технологии). Согласно теоретическим предпосылкам, компании с более высокими возможностями роста (представленные более высокими коэффициентами QТобина) показывают меньшую долговую нагрузку (табл. 6). Как это обычно замечается, компании с большими темпами роста относятся к отраслям с высоким уровнем технологии, в которых показатель М/В выше, чем 3, таким как компьютеры, электроника, медицинское оборудование, производство лекарств и финансовые услуги. Кроме того, отрасли, имеющие существенные возможности роста, в большинстве своем недокредитованы, в то время как в отраслях с небольшими возможностями роста компании перекредитовываются для того, чтобы продолжать развитие (табл. 7). В частности, в электронике, а также фармацевтической промышленности наблюдаются существенные возможности для увеличения долговой нагрузки даже после слияния, возможно, из-за для сохранения возможности осуществления дальнейших инвестиций, которые могли бы финансироваться за счет увеличения долга. Напротив, такие отрасли, как производство продуктов питания, издательское дело, сырьевая, производство промышленных товаров, транспортировки и строительства, показывают небольшие показатели $\mathrm{M} / \mathrm{B}$, положительный финансовый дефицит и превышение долговой нагрузки после слияния своего целевого уровня, вероятно, чтобы получить преимущества от налогового щита. 
Сравнение показателя М/В и долговой нагрузки (рыночной)

\begin{tabular}{|c|c|c|c|c|c|c|c|}
\hline \multirow[t]{2}{*}{ Отрасль } & \multirow[t]{2}{*}{$\begin{array}{c}\text { Кол-во } \\
\text { наблюдений }\end{array}$} & \multicolumn{3}{|c|}{ Средний уровень М/В } & \multicolumn{3}{|c|}{$\begin{array}{c}\text { Средняя долговая } \\
\text { нагрузка (на основе } \\
\text { рыночных показателей) }\end{array}$} \\
\hline & & -1 & $\mathbf{0}$ & 1 & -1 & 0 & 1 \\
\hline COMPS & 30 & 4,766 & 4,647 & 3,662 & 0,169 & 0,199 & 0,231 \\
\hline MEDEQ & 28 & 4,168 & 4,136 & 3,578 & 0,121 & 0,166 & 0,190 \\
\hline BUSSV & 87 & 3,716 & 3,690 & 2,509 & 0,177 & 0,223 & 0,250 \\
\hline DRUGS & 42 & 3,256 & 3,250 & 3,038 & 0,173 & 0,170 & 0,176 \\
\hline CHIPS & 50 & 4,389 & 2,407 & 1,980 & 0,169 & 0,211 & 0,252 \\
\hline PAPER & 12 & 2,359 & 2,366 & 2,333 & 0,277 & 0,290 & 0,295 \\
\hline LABEQ & 18 & 2,576 & 2,286 & 1,738 & 0,177 & 0,179 & 0,208 \\
\hline PERSV & 3 & 1,972 & 2,268 & 2,084 & 0,346 & 0,338 & 0,287 \\
\hline HSHLD & 12 & 2,173 & 2,105 & 2,051 & 0,282 & 0,304 & 0,295 \\
\hline INSUR & 11 & 2,538 & 2,094 & 1,807 & 0,222 & 0,339 & 0,383 \\
\hline CLTHS & 8 & 2,132 & 2,011 & 1,895 & 0,280 & 0,317 & 0,323 \\
\hline BEER & 7 & 1,968 & 1,952 & 1,807 & 0,268 & 0,245 & 0,253 \\
\hline $\mathrm{MACH}$ & 25 & 2,043 & 1,885 & 1,784 & 0,276 & 0,317 & 0,344 \\
\hline RUBBR & 3 & 1,986 & 1,873 & 2,469 & 0,238 & 0,292 & 0,319 \\
\hline FOOD & 12 & 1,934 & 1,846 & 1,652 & 0,366 & 0,385 & 0,412 \\
\hline FUN & 7 & 2,010 & 1,820 & 2,007 & 0,367 & 0,466 & 0,404 \\
\hline FIN & 1 & 2,174 & 1,802 & 0,396 & 0,238 & 0,140 & 0,396 \\
\hline AERO & 5 & 1,585 & 1,773 & 1,716 & 0,430 & 0,413 & 0,413 \\
\hline SHIPS & 1 & 2,440 & 1,727 & 1,295 & 0,431 & 0,469 & 0,605 \\
\hline HLTH & 6 & 2,124 & 1,704 & 1,738 & 0,199 & 0,277 & 0,318 \\
\hline RTAIL & 20 & 2,020 & 1,679 & 1,631 & 0,301 & 0,405 & 0,424 \\
\hline ELCEQ & 11 & 1,714 & 1,661 & 1,546 & 0,322 & 0,368 & 0,394 \\
\hline TXTLS & 2 & 1,950 & 1,657 & 1,971 & 0,295 & 0,287 & 0,226 \\
\hline GOLD & 4 & 2,372 & 1,644 & 1,675 & 0,125 & 0,141 & 0,107 \\
\hline WHLSL & 17 & 1,656 & 1,643 & 1,744 & 0,301 & 0,346 & 0,336 \\
\hline AGRIC & 1 & 2,373 & 1,553 & 1,460 & 0,171 & 0,258 & 0,178 \\
\hline TOYS & 1 & 1,342 & 1,493 & 1,457 & 0,294 & 0,237 & 0,198 \\
\hline CNSTR & 3 & 1,515 & 1,457 & 1,214 & 0,404 & 0,360 & 0,365 \\
\hline ENRGY & 53 & 1,637 & 1,439 & 1,479 & 0,303 & 0,378 & 0,384 \\
\hline MISC & 2 & 1,513 & 1,436 & 1,558 & 0,364 & 0,401 & 0,350 \\
\hline MINES & 2 & 2,707 & 1,433 & 1,258 & 0,167 & 0,329 & 0,510 \\
\hline TELCM & 25 & 1,619 & 1,430 & 1,574 & 0,410 & 0,450 & 0,509 \\
\hline CHEMS & 14 & 1,491 & 1,419 & 1,326 & 0,384 & 0,446 & 0,489 \\
\hline TRANS & 5 & 1,870 & 1,397 & 1,131 & 0,332 & 0,409 & 0,459 \\
\hline STEEL & 8 & 1,617 & 1,385 & 1,286 & 0,309 & 0,402 & 0,518 \\
\hline BOOKS & 9 & 1,615 & 1,343 & 1,315 & 0,296 & 0,487 & 0,550 \\
\hline BLDMT & 3 & 1,619 & 1,249 & 1,295 & 0,415 & 0,484 & 0,493 \\
\hline AUTOS & 8 & 1,314 & 1,245 & 1,129 & 0,456 & 0,509 & 0,598 \\
\hline MEALS & 3 & 1,637 & 1,098 & 1,060 & 0,278 & 0,376 & 0,528 \\
\hline SODA & 1 & 0,964 & 1,036 & 0,847 & 0,632 & 0,714 & 0,769 \\
\hline
\end{tabular}


Сравнение показателя М/В и дефицита заемных средств

\begin{tabular}{|c|c|c|c|c|c|c|c|}
\hline \multirow[t]{2}{*}{ Отрасль } & \multirow[t]{2}{*}{\begin{tabular}{|c|} 
Кол-во \\
наблюдений \\
\end{tabular}} & \multicolumn{3}{|c|}{ Средний уровень М/В } & \multicolumn{3}{|c|}{$\begin{array}{c}\text { Средний уровень } \\
\text { недофинансирования }\end{array}$} \\
\hline & & -1 & $\mathbf{0}$ & 1 & -1 & $\mathbf{0}$ & 1 \\
\hline COMPS & 30 & 4,766 & 4,647 & 3,662 & $-0,043$ & $-0,045$ & $-0,087$ \\
\hline MEDEQ & 28 & 4,168 & 4,136 & 3,578 & $-0,059$ & $-0,063$ & $-0,061$ \\
\hline BUSSV & 87 & 3,716 & 3,69 & 2,509 & $-0,024$ & $-0,025$ & $-0,037$ \\
\hline DRUGS & 42 & 3,256 & 3,25 & 3,038 & $-0,045$ & $-0,088$ & $-0,09$ \\
\hline CHIPS & 50 & 4,389 & 2,407 & 1,98 & $-0,046$ & $-0,061$ & $-0,085$ \\
\hline PAPER & 12 & 2,359 & 2,366 & 2,333 & $-0,03$ & $-0,055$ & $-0,075$ \\
\hline LABEQ & 18 & 2,576 & 2,286 & 1,738 & $-0,047$ & $-0,118$ & $-0,098$ \\
\hline PERSV & 3 & 1,972 & 2,268 & 2,084 & 0,102 & 0,053 & $-0,03$ \\
\hline HSHLD & 12 & 2,173 & 2,105 & 2,051 & 0,023 & $-0,003$ & $-0,027$ \\
\hline INSUR & 11 & 2,538 & 2,094 & 1,807 & $-0,059$ & 0,019 & $-0,028$ \\
\hline CLTHS & 8 & 2,132 & 2,011 & 1,895 & 0,027 & 0,015 & $-0,005$ \\
\hline BEER & 7 & 1,968 & 1,952 & 1,807 & 0,003 & $-0,075$ & $-0,086$ \\
\hline $\mathrm{MACH}$ & 25 & 2,043 & 1,885 & 1,784 & 0,017 & 0,004 & $-0,007$ \\
\hline RUBBR & 3 & 1,986 & 1,873 & 2,469 & $-0,026$ & $-0,019$ & $-0,009$ \\
\hline FOOD & 12 & 1,934 & 1,846 & 1,652 & 0,061 & 0,045 & 0,04 \\
\hline FUN & 7 & 2,01 & 1,82 & 2,007 & 0,097 & 0,137 & 0,052 \\
\hline FIN & 1 & 2,174 & 1,802 & 0,396 & 0,051 & $-0,111$ & 0,099 \\
\hline AERO & 5 & 1,585 & 1,773 & 1,716 & 0,089 & 0,05 & 0,019 \\
\hline SHIPS & 1 & 2,44 & 1,727 & 1,295 & 0,217 & 0,16 & 0,243 \\
\hline HLTH & 6 & 2,124 & 1,704 & 1,738 & $-0,044$ & $-0,049$ & $-0,042$ \\
\hline RTAIL & 20 & 2,02 & 1,679 & 1,631 & $-0,003$ & 0,059 & 0,049 \\
\hline ELCEQ & 11 & 1,714 & 1,661 & 1,546 & 0,022 & 0,043 & 0,032 \\
\hline TXTLS & 2 & 1,95 & 1,657 & 1,971 & $-0,009$ & $-0,054$ & $-0,131$ \\
\hline GOLD & 4 & 2,372 & 1,644 & 1,675 & $-0,166$ & $-0,244$ & $-0,328$ \\
\hline WHLSL & 17 & 1,656 & 1,643 & 1,744 & 0,03 & 0,042 & $-0,008$ \\
\hline AGRIC & 1 & 2,373 & 1,553 & 1,46 & $-0,095$ & $-0,074$ & $-0,187$ \\
\hline TOYS & 1 & 1,342 & 1,493 & 1,457 & 0,073 & $-0,041$ & $-0,084$ \\
\hline CNSTR & 3 & 1,515 & 1,457 & 1,214 & 0,123 & 0,035 & 0,003 \\
\hline ENRGY & 53 & 1,637 & 1,439 & 1,479 & $-0,02$ & $-0,019$ & $-0,027$ \\
\hline MISC & 2 & 1,513 & 1,436 & 1,558 & $-0,018$ & 0,039 & $-0,057$ \\
\hline MINES & 2 & 2,707 & 1,433 & 1,258 & $-0,152$ & $-0,119$ & 0,098 \\
\hline TELCM & 25 & 1,619 & 1,43 & 1,574 & 0,118 & 0,117 & 0,151 \\
\hline CHEMS & 14 & 1,491 & 1,419 & 1,326 & 0,046 & 0,07 & 0,083 \\
\hline TRANS & 5 & 1,87 & 1,397 & 1,131 & 0,055 & 0,046 & 0,067 \\
\hline STEEL & 8 & 1,617 & 1,385 & 1,286 & $-0,025$ & 0,015 & 0,077 \\
\hline BOOKS & 9 & 1,615 & 1,343 & 1,315 & 0,018 & 0,188 & 0,235 \\
\hline BLDMT & 3 & 1,619 & 1,249 & 1,295 & 0,102 & 0,119 & 0,083 \\
\hline AUTOS & 8 & 1,314 & 1,245 & 1,129 & 0,144 & 0,134 & 0,182 \\
\hline MEALS & 3 & 1,637 & 1,098 & 1,06 & $-0,007$ & 0,004 & 0,151 \\
\hline SODA & 1 & 0,964 & 1,036 & 0,847 & 0,216 & 0,37 & 0,404 \\
\hline
\end{tabular}

У компаний из отраслей с высокой волатильностью изменения в денежных потоках приводят к большому риску неплатежей по кредитам вследствие более высокой вероятности 
недостатка средств для выплаты процентов. Компании же с большим количеством материальных активов могут привлекать больше заемных средств, так как недвижимость является хорошим обеспечением. Высокими показателями долговой нагрузки при слиянии характеризуются компании из промышленных отраслей, таких как промышленные товары и товары народного потребления, услуги (приблизительно 38\%), в то время как более низкие значения уровня долга характеризуют технологические компании и компании из сферы здравоохранения (приблизительно 20-25\%) (см. табл. 8).

Интересно проанализировать изменение дефицита в заемных средствах, оцененное на основе рыночного уровня долга в различных отраслевых секторах (табл. 9). Среди отраслей, компании в которых недокредитованны до слияния, можно выделить сферы: сырьевую, здравоохранения, финансовую, коммунальных услуг, с отраслью основных материалов, имеющей наибольший финансовый дефицит - -0,078 и коммунальными услугами с наименьшей недокредитованностью - -0,002. При этом в финансовом секторе после слияния резко увеличивается размер долга и компании в целом становятся перекредитованными. Технологическая отрасль и сервис - единственные сферы, которые увеличивают кредитоемкость после слияния, вероятно, вследствие высоких возможностей дальнейшего роста. Сфера обслуживания - наиболее перекредитована среди представленных отраслей.

Таблица 8

Рыночный уровень долга в отраслевом разрезе

\begin{tabular}{|c|c|c|c|c|c|c|c|c|c|c|}
\hline \multirow[t]{2}{*}{ Отрасль } & \multirow[t]{2}{*}{$\begin{array}{c}\text { Кол-во } \\
\text { наблюдений } \\
\end{array}$} & \multicolumn{3}{|c|}{ Среднее } & \multicolumn{3}{|c|}{ Медиана } & \multicolumn{3}{|c|}{$\begin{array}{c}\text { Стандартное } \\
\text { отклонение }\end{array}$} \\
\hline & & -1 & $\mathbf{0}$ & 1 & -1 & $\mathbf{0}$ & 1 & -1 & $\mathbf{0}$ & 1 \\
\hline \multicolumn{11}{|c|}{ Сырьевые компании } \\
\hline AGRIC & 1 & 0,171 & 0,258 & 0,178 & - & - & - & - & - & - \\
\hline CHEMS & 14 & 0,384 & 0,446 & 0,489 & 0,361 & 0,421 & 0,497 & 0,111 & 0,134 & 0,114 \\
\hline STEEL & 8 & 0,309 & 0,402 & 0,518 & 0,281 & 0,381 & 0,512 & 0,144 & 0,138 & 0,192 \\
\hline GOLD & 4 & 0,125 & 0,141 & 0,107 & 0,044 & 0,068 & 0,072 & 0,171 & 0,156 & 0,092 \\
\hline MINES & 2 & 0,167 & 0,329 & 0,51 & 0,167 & 0,329 & 0,51 & 0,07 & 0,023 & 0,203 \\
\hline Итого & 29 & 0,231 & 0,315 & 0,360 & 0,213 & 0,300 & 0,398 & 0,124 & 0,113 & 0,150 \\
\hline \multicolumn{11}{|c|}{ Потребительские товары } \\
\hline FOOD & 12 & 0,366 & 0,385 & 0,412 & 0,345 & 0,396 & 0,39 & 0,143 & 0,163 & 0,184 \\
\hline SODA & 1 & 0,632 & 0,714 & 0,769 & - & - & - & - & - & - \\
\hline BEER & 7 & 0,268 & 0,245 & 0,253 & 0,174 & 0,185 & 0,185 & 0,189 & 0,139 & 0,126 \\
\hline TOYS & 1 & 0,294 & 0,237 & 0,198 & - & - & - & - & - & - \\
\hline BOOKS & 9 & 0,296 & 0,487 & 0,55 & 0,217 & 0,511 & 0,586 & 0,179 & 0,182 & 0,249 \\
\hline HSHLD & 12 & 0,282 & 0,304 & 0,295 & 0,29 & 0,293 & 0,267 & 0,109 & 0,141 & 0,123 \\
\hline CLTHS & 8 & 0,28 & 0,317 & 0,323 & 0,267 & 0,285 & 0,278 & 0,145 & 0,188 & 0,234 \\
\hline TXTLS & 2 & 0,295 & 0,287 & 0,226 & 0,295 & 0,287 & 0,227 & 0,13 & 0,017 & 0,053 \\
\hline ELCEQ & 11 & 0,322 & 0,368 & 0,394 & 0,304 & 0,428 & 0,439 & 0,108 & 0,127 & 0,146 \\
\hline AUTOS & 8 & 0,456 & 0,509 & 0,598 & 0,481 & 0,581 & 0,602 & 0,194 & 0,178 & 0,092 \\
\hline PAPER & 12 & 0,277 & 0,29 & 0,295 & 0,234 & 0,208 & 0,193 & 0,147 & 0,165 & 0,158 \\
\hline MISC & 2 & 0,364 & 0,401 & 0,35 & 0,346 & 0,401 & 0,35 & 0,106 & 0,1 & 0,011 \\
\hline Итого & 85 & 0,344 & 0,379 & 0,389 & 0,295 & 0,358 & 0,352 & 0,145 & 0,140 & 0,138 \\
\hline \multicolumn{11}{|l|}{ Финансы } \\
\hline INSUR & 11 & 0,222 & 0,339 & 0,383 & 0,229 & 0,238 & 0,277 & 0,122 & 0,2 & 0,241 \\
\hline FIN & 1 & 0,238 & 0,14 & 0,396 & - & - & - & - & - & - \\
\hline Итого & 12 & 0,230 & 0,240 & 0,390 & 0,229 & 0,238 & 0,277 & 0,122 & 0,200 & 0,241 \\
\hline
\end{tabular}




\begin{tabular}{|c|c|c|c|c|c|c|c|c|c|c|}
\hline \multicolumn{11}{|c|}{ Здравоохранение } \\
\hline HLTH & 6 & 0,199 & 0,277 & 0,318 & 0,196 & 0,243 & 0,304 & 0,081 & 0,137 & 0,183 \\
\hline MEDEQ & 28 & 0,121 & 0,166 & 0,19 & 0,098 & 0,132 & 0,136 & 0,094 & 0,149 & 0,15 \\
\hline DRUGS & 42 & 0,173 & 0,17 & 0,176 & 0,15 & 0,139 & 0,156 & 0,104 & 0,108 & 0,107 \\
\hline Итого & 76 & 0,164 & 0,204 & 0,228 & 0,148 & 0,171 & 0,199 & 0,093 & 0,131 & 0,147 \\
\hline \multicolumn{11}{|c|}{ Промышленные товары } \\
\hline RUBBR & 3 & 0,238 & 0,292 & 0,319 & 0,126 & 0,103 & 0,081 & 0,221 & 0,343 & 0,439 \\
\hline BLDMT & 3 & 0,415 & 0,484 & 0,493 & 0,262 & 0,362 & 0,35 & 0,265 & 0,211 & 0,248 \\
\hline CNSTR & 3 & 0,404 & 0,36 & 0,365 & 0,341 & 0,3 & 0,406 & 0,179 & 0,199 & 0,176 \\
\hline $\mathrm{MACH}$ & 25 & 0,276 & 0,317 & 0,344 & 0,249 & 0,336 & 0,297 & 0,174 & 0,192 & 0,215 \\
\hline AERO & 5 & 0,43 & 0,413 & 0,413 & 0,468 & 0,411 & 0,431 & 0,095 & 0,098 & 0,103 \\
\hline SHIPS & 1 & 0,431 & 0,469 & 0,605 & - & - & - & - & - & - \\
\hline Итого & 40 & 0,366 & 0,389 & 0,423 & 0,289 & 0,302 & 0,313 & 0,187 & 0,209 & 0,236 \\
\hline \multicolumn{11}{|l|}{ Услуги } \\
\hline FUN & 7 & 0,367 & 0,466 & 0,404 & 0,358 & 0,522 & 0,357 & 0,192 & 0,222 & 0,221 \\
\hline PERSV & 3 & 0,346 & 0,338 & 0,287 & 0,385 & 0,332 & 0,259 & 0,24 & 0,26 & 0,221 \\
\hline TRANS & 5 & 0,332 & 0,409 & 0,459 & 0,406 & 0,43 & 0,461 & 0,153 & 0,123 & 0,088 \\
\hline WHLSL & 17 & 0,301 & 0,346 & 0,336 & 0,251 & 0,275 & 0,292 & 0,167 & 0,186 & 0,175 \\
\hline RTAIL & 20 & 0,301 & 0,405 & 0,424 & 0,269 & 0,421 & 0,38 & 0,135 & 0,177 & 0,191 \\
\hline MEALS & 3 & 0,278 & 0,376 & 0,528 & 0,129 & 0,34 & 0,466 & 0,301 & 0,157 & 0,183 \\
\hline Итого & 55 & 0,321 & 0,390 & 0,406 & 0,300 & 0,387 & 0,369 & 0,198 & 0,188 & 0,180 \\
\hline \multicolumn{11}{|c|}{ Высокие технологии } \\
\hline TELCM & 25 & 0,41 & 0,45 & 0,509 & 0,424 & 0,465 & 0,472 & 0,152 & 0,151 & 0,227 \\
\hline BUSSV & 87 & 0,177 & 0,223 & 0,25 & 0,138 & 0,176 & 0,21 & 0,132 & 0,165 & 0,184 \\
\hline COMPS & 30 & 0,169 & 0,199 & 0,231 & 0,119 & 0,112 & 0,169 & 0,17 & 0,208 & 0,23 \\
\hline CHIPS & 50 & 0,169 & 0,211 & 0,252 & 0,109 & 0,223 & 0,262 & 0,153 & 0,172 & 0,187 \\
\hline LABEQ & 18 & 0,177 & 0,179 & 0,208 & 0,148 & 0,154 & 0,16 & 0,146 & 0,112 & 0,135 \\
\hline Итого & 210 & 0,220 & 0,252 & 0,290 & 0,188 & 0,226 & 0,255 & 0,151 & 0,162 & 0,193 \\
\hline \multicolumn{11}{|c|}{ Коммунальные услуги } \\
\hline ENERGY & 53 & 0,303 & 0,378 & 0,384 & 0,276 & 0,357 & 0,374 & 0,15 & 0,188 & 0,195 \\
\hline
\end{tabular}

Таблица 9

Уровень недофинансирования в разрезе по отраслям

\begin{tabular}{|c|c|c|c|c|c|c|c|c|c|c|}
\hline \multirow[t]{2}{*}{ Отрасль } & \multirow{2}{*}{$\begin{array}{c}\text { Кол-во } \\
\text { наблю- } \\
\text { дений }\end{array}$} & \multicolumn{3}{|c|}{ Средняя } & \multicolumn{3}{|c|}{ Медиана } & \multicolumn{3}{|c|}{$\begin{array}{c}\text { Стандартное } \\
\text { отклонение }\end{array}$} \\
\hline & & -1 & $\mathbf{0}$ & 1 & -1 & $\mathbf{0}$ & 1 & -1 & $\mathbf{0}$ & 1 \\
\hline \multicolumn{11}{|c|}{ Сырьевые компании } \\
\hline AGRIC & 1 & $-0,095$ & $-0,074$ & $-0,187$ & - & - & - & - & - & - \\
\hline CHEMS & 14 & 0,046 & 0,07 & 0,083 & 0,021 & 0,042 & 0,089 & 0,107 & 0,142 & 0,121 \\
\hline STEEL & 8 & $-0,025$ & 0,015 & 0,077 & $-0,031$ & $-0,022$ & 0,105 & 0,143 & 0,134 & 0,19 \\
\hline GOLD & 4 & $-0,166$ & $-0,244$ & $-0,328$ & $-0,217$ & $-0,288$ & $-0,351$ & 0,148 & 0,144 & 0,106 \\
\hline MINES & 2 & $-0,152$ & $-0,119$ & 0,098 & $-0,152$ & $-0,119$ & 0,098 & 0,078 & 0,103 & 0,255 \\
\hline Итого & 29 & $-0,078$ & $-0,070$ & $-0,051$ & $-0,095$ & $-0,097$ & $-0,015$ & 0,119 & 0,131 & 0,168 \\
\hline
\end{tabular}




\begin{tabular}{|c|c|c|c|c|c|c|c|c|c|c|}
\hline FOOD & 12 & 0,061 & 0,045 & 0,04 & 0,06 & 0,057 & 0,062 & 0,111 & 0,13 & 0,148 \\
\hline SODA & 1 & 0,216 & 0,37 & 0,404 & - & - & - & - & - & - \\
\hline BEER & 7 & 0,003 & $-0,075$ & $-0,086$ & $-0,077$ & $-0,129$ & $-0,133$ & 0,161 & 0,119 & 0,097 \\
\hline TOYS & 1 & 0,073 & $-0,041$ & $-0,084$ & - & - & - & - & - & - \\
\hline BOOKS & 9 & 0,018 & 0,188 & 0,235 & $-0,042$ & 0,185 & 0,259 & 0,193 & 0,185 & 0,254 \\
\hline HSHLD & 12 & 0,023 & $-0,003$ & $-0,027$ & 0,017 & $-0,017$ & $-0,041$ & 0,082 & 0,12 & 0,112 \\
\hline CLTHS & 8 & 0,027 & 0,015 & $-0,005$ & 0,011 & $-0,023$ & $-0,041$ & 0,113 & 0,162 & 0,213 \\
\hline TXTLS & 2 & $-0,009$ & $-0,054$ & $-0,131$ & $-0,009$ & $-0,054$ & $-0,131$ & 0,126 & 0,028 & 0,049 \\
\hline ELCEQ & 11 & 0,022 & 0,043 & 0,032 & 0,023 & 0,095 & 0,07 & 0,097 & 0,116 & 0,128 \\
\hline AUTOS & 8 & 0,144 & 0,134 & 0,182 & 0,155 & 0,203 & 0,184 & 0,158 & 0,175 & 0,112 \\
\hline PAPER & 12 & $-0,03$ & $-0,055$ & $-0,075$ & $-0,063$ & $-0,133$ & $-0,141$ & 0,1 & 0,115 & 0,101 \\
\hline MISC & 2 & $-0,018$ & 0,039 & $-0,057$ & $-0,018$ & 0,039 & $-0,057$ & 0,115 & 0,104 & 0,008 \\
\hline Итого & 85 & 0,044 & 0,051 & 0,036 & 0,006 & 0,022 & 0,003 & 0,126 & 0,125 & 0,122 \\
\hline \multicolumn{11}{|c|}{ Финансовый сектор } \\
\hline INSUR & 11 & $-0,059$ & 0,019 & $-0,028$ & $-0,053$ & 0,006 & $-0,068$ & 0,087 & 0,169 & 0,147 \\
\hline FIN & 1 & 0,051 & $-0,111$ & 0,099 & - & - & - & - & - & - \\
\hline Итого & 12 & $-0,004$ & $-0,046$ & 0,036 & $-0,053$ & 0,006 & $-0,068$ & 0,087 & 0,169 & 0,147 \\
\hline \multicolumn{11}{|c|}{ Здравоохранение } \\
\hline HLTH & 6 & $-0,044$ & $-0,049$ & $-0,042$ & $-0,069$ & $-0,083$ & $-0,074$ & 0,089 & 0,095 & 0,127 \\
\hline MEDEQ & 28 & $-0,059$ & $-0,063$ & $-0,061$ & $-0,067$ & $-0,096$ & $-0,107$ & 0,058 & 0,104 & 0,13 \\
\hline DRUGS & 42 & $-0,045$ & $-0,088$ & $-0,09$ & $-0,073$ & $-0,107$ & $-0,123$ & 0,084 & 0,087 & 0,101 \\
\hline Итого & 76 & $-0,049$ & $-0,067$ & $-0,064$ & $-0,070$ & $-0,095$ & $-0,101$ & 0,077 & 0,095 & 0,119 \\
\hline \multicolumn{11}{|c|}{ Промышленные товары } \\
\hline RUBBR & 3 & $-0,026$ & $-0,019$ & $-0,009$ & $-0,102$ & $-0,195$ & $-0,235$ & 0,179 & 0,312 & 0,391 \\
\hline BLDMT & 3 & 0,102 & 0,119 & 0,083 & $-0,043$ & 0,003 & $-0,064$ & 0,252 & 0,202 & 0,255 \\
\hline CNSTR & 3 & 0,123 & 0,035 & 0,003 & 0,135 & 0,008 & 0,094 & 0,172 & 0,202 & 0,204 \\
\hline $\mathrm{MACH}$ & 25 & 0,017 & 0,004 & $-0,007$ & $-0,023$ & 0,025 & $-0,005$ & 0,14 & 0,164 & 0,193 \\
\hline AERO & 5 & 0,089 & 0,05 & 0,019 & 0,09 & 0,043 & 0,003 & 0,116 & 0,098 & 0,096 \\
\hline SHIPS & 1 & 0,217 & 0,16 & 0,243 & - & - & - & - & - & - \\
\hline Итого & 40 & 0,087 & 0,058 & 0,055 & 0,011 & $-0,023$ & $-0,041$ & 0,172 & 0,196 & 0,228 \\
\hline \multicolumn{11}{|l|}{ Услуги } \\
\hline FUN & 7 & 0,097 & 0,137 & 0,052 & 0,108 & 0,177 & $-0,001$ & 0,18 & 0,201 & 0,193 \\
\hline PERSV & 3 & 0,102 & 0,053 & $-0,03$ & 0,178 & 0,092 & $-0,058$ & 0,16 & 0,183 & 0,109 \\
\hline TRANS & 5 & 0,055 & 0,046 & 0,067 & 0,109 & 0,008 & 0,049 & 0,128 & 0,079 & 0,109 \\
\hline WHLSL & 17 & 0,03 & 0,042 & $-0,008$ & 0,031 & 0,012 & 0,019 & 0,141 & 0,145 & 0,135 \\
\hline RTAIL & 20 & $-0,003$ & 0,059 & 0,049 & $-0,02$ & 0,107 & 0,009 & 0,131 & 0,174 & 0,198 \\
\hline MEALS & 3 & 0,278 & 0,376 & 0,528 & 0,129 & 0,34 & 0,466 & 0,301 & 0,157 & 0,183 \\
\hline Итого & 55 & 0,093 & 0,119 & 0,110 & 0,089 & 0,123 & 0,081 & 0,174 & 0,157 & 0,155 \\
\hline \multicolumn{11}{|c|}{ Высокие технологии } \\
\hline TELCM & 25 & 0,118 & 0,117 & 0,151 & 0,059 & 0,138 & 0,083 & 0,157 & 0,151 & 0,226 \\
\hline BUSSV & 87 & $-0,024$ & $-0,025$ & $-0,037$ & $-0,04$ & $-0,051$ & $-0,055$ & 0,106 & 0,132 & 0,154 \\
\hline COMPS & 30 & $-0,043$ & $-0,045$ & $-0,087$ & $-0,072$ & $-0,099$ & $-0,168$ & 0,118 & 0,162 & 0,214 \\
\hline CHIPS & 50 & $-0,046$ & $-0,061$ & $-0,085$ & $-0,048$ & $-0,084$ & $-0,081$ & 0,119 & 0,146 & 0,166 \\
\hline LABEQ & 18 & $-0,047$ & $-0,118$ & $-0,098$ & $-0,075$ & $-0,131$ & $-0,135$ & 0,112 & 0,119 & 0,147 \\
\hline Итого & 210 & $-0,008$ & $-0,026$ & $-0,031$ & $-0,035$ & $-0,045$ & $-0,071$ & 0,122 & 0,142 & 0,181 \\
\hline
\end{tabular}




\begin{tabular}{|l|l|l|l|l|l|l|l|l|l|l|}
\hline Коммунальные услуги \\
\hline ENERGY & 53 & $-0,02$ & $-0,019$ & $-0,027$ & $-0,043$ & $-0,044$ & $-0,04$ & 0,134 & 0,176 & 0,182 \\
\hline
\end{tabular}

Мы разделили выборку на три подвыборки в порядке возрастания дефицита заемных средств после слияния и исследуем изменения в характеристиках компаний. У всех компаний наблюдается снижение показателя М/B после слияния с самым большим снижением в подвыборке с наибольшей степенью недокредитованности $(-0,52)$ и самом маленьком $(-0,03)$ в подвыборке с перекредитованными компаниями. Во всех группах наблюдается уменьшение материальных активов. Что касается переменной доходности, снижение наблюдается только для группы недокредитованных компаний. Причиной снижения доходности может быть рост коммерческих расходов. Очевидно, все три подвыборки показывают увеличение размера компаний после слияния (табл. 10).

Таблица 10

Изменения характеристик компаний после слияния

\begin{tabular}{|l|l|l|l|}
\hline Рапеl А, Недокредитованные компании (211 компаний) \\
\hline Переменная & Средняя & Медиана & $\begin{array}{l}\text { Стандартное } \\
\text { отклонение }\end{array}$ \\
\hline Изменение M/Bt & $-0,5243$ & $-0,0259$ & 3,2486 \\
\hline Изменение PPEt & $-0,0091$ & $-0,0086$ & 0,0500 \\
\hline Изменение EBITDAt & $-0,0169$ & $-0,0070$ & 0,0596 \\
\hline Изменение SEXPt & 0,0068 & 0,0016 & 0,0714 \\
\hline Изменение SIZEt & 0,2688 & 0,2196 & 0,3205 \\
\hline Рапеl В, Фирмы с нормальным уровнем долга (229 компаний) \\
\hline Изменение M/Bt & $-0,2383$ & $-0,1004$ & 1,3148 \\
\hline Изменение PPEt & $-0,0156$ & $-0,0061$ & 0,0561 \\
\hline Изменение EBITDAt & 0,0041 & 0,0055 & 0,0485 \\
\hline Изменение SEXPt & $-0,0028$ & 0,0018 & 0,1461 \\
\hline Изменение SIZEt & 0,2247 & 0,1628 & 0,3227 \\
\hline Рапеl С, Перекредитованные компании (122 компании) \\
\hline Изменение M/Bt & $-0,0329$ & $-0,1922$ & 3,7761 \\
\hline Изменение PPEt & $-0,0147$ & $-0,0097$ & 0,0802 \\
\hline Изменение EBITDAt & 0,0209 & 0,0033 & 0,1188 \\
\hline Изменение SEXPt & $-0,0003$ & 0,0011 & 0,0503 \\
\hline Изменение SIZEt & 0,2787 & 0,2065 & 0,3124 \\
\hline
\end{tabular}

\section{3. Метод оплаты, премии и характеристики синергии}

Мы обнаружили, что 5\% слияний были профинансированы за счет наличных средств, $30 \%$ - за счет акций, и остальные - с использованием комбинированного способа оплаты (табл. 11).

Таблица 11

Способ оплаты

\begin{tabular}{|llll|}
\hline \multicolumn{1}{|c|}{ Способ } & Кол-во & \% \\
\hline Наличные & 29 & 5,16 & \\
Акции & 170 & 30,25 & \\
Комбинированный & 363 & 64,59 & \\
\hline
\end{tabular}

Средний размер премии составляет приблизительно $31 \%$, с самыми высокими (в среднем) уровнями в секторе здравоохранения (38\%) и самыми низкими - в секторе услуг (23\%). Отраслями, где премии превышают 40\%, являются сфера строительных материалов 
(68\%), автомобилестроение (49\%), текстильная промышленность (48\%), производство продуктов питания, напитков, химическая промышленность и бытовые услуги (41\%). Премии в среднем 9-11\% были уплачены в таких отраслях, как телекоммуникации, рестораны и отели (данные доступны по отдельному запросу). Самая высокая стоимость сделки по отношению к балансовой стоимости активов наблюдается в торговой отрасли $(5500 \%)$, машиностроении (400\%), пивной (500\%) и транспортной (100\%) сферах, а наименьшие показатели - в производстве промышленных товаров (44\%). Интересно, что около $57 \%$ слияний происходят в пределах одной отрасли. При этом большинство компаний увеличивает долговую нагрузку независимо от того, произошло ли слияние в пределах одной отрасли (62\%) или было межотраслевым (57\%).

Теория предполагает, что внутриотраслевые сделки направлены на получение прибыли за счет синергетических эффектов (как в результате оптимизации операционной деятельности, так и за счет комплементарности ресурсной базы (Agliardi, 2011)). Возможности для синергии приводят к более высоким ценовым предложениям от компаниипокупателя. Измеряя схожесть отраслей поглощаемой компании и покупателя по кодам SIC, мы обнаружили более высокую премию у внутриотраслевых сделок (33\%), против межотраслевых слияний (28\%).

Давайте исследуем выборку из 2217 слияний между публичными американскими компаниями за период с 1977 по 2010 год. Данная выборка была собрана на основании базы по слияниям и поглощениям Thomson Reuters SDC Platinum. Описательная статистика сделок по слиянию представлена в таблице 12.

Таблица 12

Описательная статистика сделок

\begin{tabular}{|c|c|c|c|c|}
\hline & $\begin{array}{c}\text { К-во } \\
\text { наблюдений }\end{array}$ & Средняя & Медиана & $\begin{array}{c}\text { Ст, } \\
\text { отклонение }\end{array}$ \\
\hline Оплата наличными & $95(4,29 \%)$ & & & \\
\hline Премия & & 33,031 & 25,000 & 29,803 \\
\hline Объем сделки/EBITDA & & 31,596 & 17,521 & 40,439 \\
\hline Объем сделки/продажи & & 4,893 & 2,846 & 7,852 \\
\hline Объем сделки/чистая & & 80,167 & 33,495 & 155,064 \\
\hline Смешанная оплата & $\begin{array}{l}1503 \\
(67,79 \%)\end{array}$ & & & \\
\hline Премия & & 34,555 & 27,210 & 38,412 \\
\hline Объем сделки/EBITDA & & 29,400 & 11,393 & 124,224 \\
\hline Объем сделки/продажи & & 7,040 & 1,667 & 56,581 \\
\hline $\begin{array}{l}\text { Объем } \\
\text { прибыль }\end{array}$ & & 80,093 & 29,835 & 306,283 \\
\hline Оплата акциями & $\begin{array}{l}619 \\
(27,92 \%)\end{array}$ & & & \\
\hline Премия & & 32,340 & 27,700 & 34,201 \\
\hline Объем сделки/EBITDA & & 81,749 & 15,640 & 770,563 \\
\hline Объем сделки/продажи & & 20,861 & 3,062 & 167,401 \\
\hline $\begin{array}{l}\text { Объем } \quad \text { сделки/чистая } \\
\text { прибыль }\end{array}$ & & 90,766 & 33,796 & 276,3688 \\
\hline Итого & $2217(100 \%)$ & & & \\
\hline Премия & & 33,809 & 27,210 & 36,795 \\
\hline Объем сделки/EBITDA & & 43,618 & 12,364 & 413,582 \\
\hline Объем сделки/продажи & & 10,874 & 2,074 & 100,737 \\
\hline $\begin{array}{l}\text { Объем } \\
\text { прибыль }\end{array}$ & & 82,980 & 31,430 & 293,246 \\
\hline
\end{tabular}


В частности, мы видим, что только приблизительно 5\% всех сделок оплачиваются наличными средствами, и приблизительно $28 \%$ - акциями. Премия при оплате акциями больше, чем при оплате наличными. Однако размер сделок, измеренный при помощи показателя EBITDA, ниже при оплате наличными и больше при оплате за счет акций. В работе Мартыновой (Martynova, 2009) различают средства платежа и средства финансирования: эти два понятия не эквивалентны, и решение покупателя об источниках финансирования поглощения часто зависит от выбора средств платежа. Сделка может быть оплачена наличными средствами или собственным капиталом, но основные источники финансирования включают больше альтернатив. Слияния, профинансированные за счет собственного капитала, как ожидается, приносят пониженную доходность покупателям. Это происходит потому, что инвесторы воспринимают попытку покупателя оплатить сделку за счет собственного капитала как сигнал переоценки акций покупателя, и поэтому курс акций падает. Данный эффект переоценки является еще более явным, если слияние полностью профинансировано и оплачено собственным капиталом. Родес-Кропф (Rhodes-Kropf, 2004) показывает, что переоцененные компании-покупатели используют акционерный капитал, чтобы купить недооцененные компании и на долгосрочном горизонте после устранения переоценки получить преимущества от неправильной оценки. Оплата акциями может также интерпретироваться рынком как отрицательный сигнал относительно потенциальной синергии от слияния. Если качество активов компании-цели довольно сомнительно, покупатели склонны платить акциями, чтобы передать часть рисков невозможности реализации синергии акционерам компании-цели. В случае если сделка финансируется за счет заемных средств, наблюдается положительная реакция рынка. Это происходит из-за того, что долговое финансирование является сигналом об отсутствии переоценки акций покупателя. При недостатке внутренних источников финансирования менеджмент привлекает заемные средства, если стоимость акций их компании недооценена или если размещение акций опасно, поскольку это может привести к падению их стоимости. Наконец, финансирование сделок за счет внутренних источников часто приводит к отрицательной реакции рынка после объявления о поглощении, потому что это может указывать на то, что слияние осуществляется вследствие наличия свободных денежных средств. Как указывает в своей работе о теории агентских издержек Дженсен (Jensen, 1986), большие запасы денежных средств побуждают менеджмент инициировать слияния с целью построения империй, что зачастую может уменьшать акционерную стоимость. Однако чтобы определить источник финансирования приобретения, необходимо располагать большей информацией о сделке.

\section{3. Волатильность и асимметрия доходности компаний}

Начиная с работы Лиланд (Leland, 2007) признано, что чистая финансовая синергия может возникнуть при слиянии, если корреляция между денежными потоками компании покупателя и цели низкая и волатильность денежных потоков также низкая, при этом преимущества от слияния возрастают при больших размерах компании и больших издержках банкротства, поскольку диверсификация снижает риск дефолта. У компаний с высокой асимметрией доходности при росте волатильности компании-цели преимущества от слияния сокращаются и могут стать отрицательными (если различие между двумя волатильностями является существенным). Таким образом, если волатильности компаний различаются существенно, предпочтительнее разделение компаний. Фактически фирма с высокой волатильностью вряд ли будет стремиться к слиянию с компанией, намного меньшей по размеру, особенно если у той компании низкая волатильность. Данные выводы верны не только для финансовой синергии, но и для операционной, а также при существенном улучшении результатов после слияния за счет использования комплементарности ресурсной базы покупателя и компании цели (для более подробного анализа альтернативных эффектов синергии см. работу Аглиарди (Agliardi, 2011)). 
Также распределение денежных потоков компании может иметь значение. В работе Шнейдер (Schneider, 2010) утверждается, что вероятность азартного поведения менеджмента и использование теории вероятностей при решениях о поглощении может иметь важное значение. Если точнее, то менеджмент компании-покупателя, который использует вероятностный анализ, склонен переоценивать вероятность того, что доходы после слияния будут высоки. Этот факт более очевиден для компаний-целей с положительной асимметрией будущих доходов. Таким образом, покупатели переплачивают при поглощении, что больше похоже на азартную игру. Кроме того, если менеджмент переоценивает потенциальную доходность приобретаемой компании, синергия, при прочих равных условиях, имеет тенденцию быть ниже при слияниях, которые имеют составляющую рисковой игры. Эти соображения заставляют нас добавлять другие характеристики распределения будущих доходов и, в случае повышенной асимметрии, проверять наличие связи между методами оплаты и снижением риска в слияниях, а также изменение волатильности и асимметрии после слияния.

Мы использовали выборку на основании базы по слияниям и поглощениям Thomson Reuters SDC Platinum по сделкам, совершенным в период 2000-2007 годов. Мы выбрали только те компании-цели и покупателей, по которым есть ежемесячные данные о доходности акций из базы данных Center for Research in Security Prices (CSRP) как минимум за период 36 месяцев до и после слияния. Итоговая выборка включает в себя 294 компании. В таблице 13 представлена статистика по изменению волатильности и асимметрии после закрытия сделки. Важно заметить, что положительные и отрицательные изменения распределены примерно в равных пропорциях. Хотя результаты показывают, что большинство компаний после слияния показывают уменьшение волатильности и асимметрии, это не может служить моделью поведения компаний после слияния. Поэтому важно особенно внимательно анализировать подобные изменения в разрезе отраслей (см. табл. 14).

Таблица 13

Описательная статистика волатильности и асимметрии после слияния

\begin{tabular}{|c|c|c|c|c|c|}
\hline & Мин, & Макс, & Среднее & Медиана & $\begin{array}{l}\text { Ст, } \\
\text { отклонение }\end{array}$ \\
\hline Волатильность цели & $4,33 \%$ & $58,56 \%$ & $17,48 \%$ & $15,36 \%$ & $8,88 \%$ \\
\hline Волатильность покупателя & $3,77 \%$ & $37,52 \%$ & $12,67 \%$ & $10,5 \%$ & $7,3 \%$ \\
\hline Волатильность после слияния & $2,72 \%$ & $63,36 \%$ & $12,15 \%$ & $10,15 \%$ & $7,63 \%$ \\
\hline $\begin{array}{l}\text { Относительный } \\
\text { волатильности }\end{array}$ & - & - & 1,58 & 1,37 & 0,84 \\
\hline Асимметрия цели & 0,02 & 4,27 & 0,73 & 0,58 & 0,90 \\
\hline Асимметрия покупателя & 0 & 3,60 & 0,28 & 0,19 & 0,67 \\
\hline $\begin{array}{l}\text { Асимметрия цели после } \\
\text { слияния }\end{array}$ & 0 & 5,20 & 0,11 & 0,02 & 0,89 \\
\hline $\begin{array}{l}\text { Изменение волатильности } \\
\text { асимметрии после слияния }\end{array}$ & и & \multicolumn{2}{|c|}{ Увеличение } & \multicolumn{2}{|c|}{ Уменьшение } \\
\hline Волатильность & & 142 & $48,3 \%$ & 152 & $.7 \%$ \\
\hline Асимметрия & & 146 & $49,66 \%$ & 148 & $34 \%$ \\
\hline
\end{tabular}

Значительная доля компаний в отрасли основных материалов (приблизительно 84\%) и в финансовом секторе $(60 \%)$ показывают увеличение волатильности при снижении 
асимметрии. Подобные показатели изменчивости волатильности и асимметрии также наблюдаются в секторе услуг и технологических отраслях, где оба параметра возрастают после закрытия сделки. Интересно, что в наукоемких секторах (за исключением химической отрасли) в среднем сокращается и волатильность, и асимметрия. Такие показатели могут быть объяснены следующим образом: в отрасли основных материалов большинство слияний осуществляются в пределах отрасли между компаниями с положительной корреляцией. Таким образом, объединение таких компаний в высоковолатильном секторе приводит к увеличению волатильности доходности акций.

Используя SIC-коды и корреляции, мы пытаемся различить слияния, осуществленные между связанными компаниями, и слияния, осуществленные с целью диверсификации (табл. 14). В результате мы можем утверждать, что $67 \%$ слияний осуществляется между связанными компаниями, в то время как доля компаний с положительной корреляцией выше 0,2 составляет только 56\%. Если мы считаем фирмы с отрицательной корреляцией, получим лишь 15\% диверсифицированных слияний во всей выборке.

Таблица 14

Доля диверсифицированных и связанных слияний в разрезе отраслей

\begin{tabular}{|l|l|l|l|l|l|l|l|}
\hline Отраслевой сектор & К-во & H+ & H- & L+ & L- & SIC R & SIC D \\
\hline Сырьевые компании & 13 & 53,85 & 0,00 & 23,08 & 23,08 & 61,54 & 38,46 \\
Потребительские & 22 & 68,18 & 4,55 & 22,73 & 4,55 & 45,45 & 54,55 \\
товары & 10 & 70,00 & 0,00 & 30,00 & 0,00 & 70,00 & 30,00 \\
Финансовый & 46 & 43,48 & 4,35 & 36,96 & 15,22 & 80,43 & 19,57 \\
Здравоохранение & 20 & 55,00 & 0,00 & 30,00 & 15,00 & 35,00 & 65,00 \\
Промышленные & 24 & 62,50 & 0,00 & 29,17 & 8,33 & 62,50 & 37,50 \\
товары & 133 & 54,89 & 1,50 & 27,82 & 15,79 & 60,90 & 39,10 \\
Услуги & 26 & 65,38 & 0,00 & 23,08 & 11,54 & 100 & 0,00 \\
Технологии & 294 & 56,12 & 1,70 & 28,57 & 13,61 & 67,35 & 32,65 \\
Ком. услуги & \multicolumn{7}{|l|l|l|l|}{} \\
Итого & 56,12 & 43,88 & & 84,69 & 15,31 \\
\hline
\end{tabular}

Два основных критерия, которые мы использовали для определения различий между связанным слиянием и диверсифицированным, - это корреляция доходностей акций покупателя и компании-цели, и классификация отрасли компании по коду SIC.

При отраслевом анализе мы наблюдаем, что межотраслевые слияния с отрицательной корреляцией довольно часто происходят в таких секторах, как сырьевая и здравоохранение. Однако, если мы отдельно рассмотрим технологическую и высокотехнологическую отрасли, мы наблюдаем только $17 \%$ слияний между компаниями с отрицательной корреляцией доходностей акций. Данные выводы совпадают с результатами Макри (Makri, 2007), который исследует взаимозависимость технологий и знаний в слияниях, а также с работой РодесКропф (Rhodes-Kropf, 2004), в которой авторы утверждают, что компании с комплементарными активами или технологиями должны объединяться, изменяя границы компаний для установления общего контроля над подобного рода активами. Кроме того, вопреки предпосылкам агентской теории, Макри обнаружил обратную связь между высоким первоначальным уровнем риска и диверсификацией. Также мы замечаем, что в слияниях, где компании-цели имели волатильность и асимметрию выше среднего, премия при слиянии в среднем выше (37\%) по сравнению премией в 30\% у компаний с низкой волатильностью и асимметрией (табл. 15). Это частично доказывает теорию азартного поведения менеджмента по отношению к корпоративным поглощениям 
Таблица 15

Средняя премия при различных значениях волатильности и асимметрии, \%

\begin{tabular}{|l|l|l|}
\hline & $\begin{array}{c}\text { Высокая волатильность и } \\
\text { асимметрия }\end{array}$ & $\begin{array}{c}\text { Низкая волатильность и } \\
\text { асимметрия }\end{array}$ \\
\hline Средняя премия & 36,77 & 30,39 \\
\hline
\end{tabular}

Таблица 16

Наукоемкие отрасли и классификация слияний

\begin{tabular}{|c|c|c|c|c|c|c|c|c|c|c|c|c|c|}
\hline \multirow{2}{*}{$\begin{array}{c}\text { Наукоемкие } \\
\text { отрасли }\end{array}$} & \multirow[t]{2}{*}{$\mathbf{N}$} & \multicolumn{2}{|r|}{ H+ } & \multicolumn{2}{|r|}{ H- } & \multicolumn{2}{|r|}{$\mathbf{L}+$} & \multicolumn{2}{|r|}{ L- } & \multicolumn{2}{|r|}{$\mathbf{W}$} & \multicolumn{2}{|r|}{$\mathbf{A}$} \\
\hline & & \# & $\%$ & \# & $\%$ & \# & $\%$ & \# & $\%$ & \# & $\%$ & \# & $\%$ \\
\hline Фармацевтика & 26 & 11 & 42,31 & 2 & 7,69 & 9 & 34,62 & 4 & 15,38 & 22 & 84,62 & 4 & 15,38 \\
\hline Химия & 5 & 3 & 60,00 & 0 & 0,00 & 2 & 40,00 & 0 & 0,00 & 4 & 80,00 & 1 & 20,00 \\
\hline Электроника & 38 & 24 & 63,16 & 1 & 2,63 & 8 & 21,05 & 5 & 13,16 & 21 & 87,50 & 17 & 12,50 \\
\hline Итого & 69 & 38 & 55,07 & 3 & 4,35 & 19 & 27,54 & 9 & 13,04 & 47 & 68,12 & 22 & 31,88 \\
\hline
\end{tabular}

Наукоемкие отрасли и влияние слияний на волатильность и асимметрию

\begin{tabular}{|c|c|c|c|c|c|c|c|c|c|}
\hline \multirow{2}{*}{$\begin{array}{c}\text { Наукоемкие } \\
\text { отрасли }\end{array}$} & \multirow[t]{2}{*}{$\mathbf{N}$} & \multicolumn{2}{|c|}{$\begin{array}{c}\text { Увеличение } \\
\text { волатильности }\end{array}$} & \multicolumn{2}{|c|}{$\begin{array}{c}\text { Уменьшение } \\
\text { волатильности }\end{array}$} & \multicolumn{2}{|c|}{$\begin{array}{l}\text { Увеличение } \\
\text { асимметрии }\end{array}$} & \multicolumn{2}{|c|}{$\begin{array}{l}\text { Уменьшение } \\
\text { асимметрии }\end{array}$} \\
\hline & & \# & $\%$ & \# & $\%$ & \# & $\%$ & \# & $\%$ \\
\hline Фармацевтика & 26 & 10 & 38,46 & 16 & 61,54 & 12 & 46,15 & 14 & 53,85 \\
\hline Химия & 5 & 5 & 100 & 0 & 0 & 1 & 20 & 4 & 80 \\
\hline Электроника & 38 & 15 & 39,47 & 23 & 60,53 & 16 & 42,11 & 22 & 57,9 \\
\hline Итого & 69 & 30 & 43,48 & 39 & 56,52 & 29 & 42,03 & 40 & 57,97 \\
\hline
\end{tabular}

Описательная статистика (табл. 17) показывает, что большая часть слияний в выборке оплачена за счет наличных средств. Однако сделки, оплаченные наличными, в среднем меньше по размеру. Премии выше при сделках, оплаченных акциями, что наблюдается не так часто при оплате наличными или гибридном финансировании.

Таблица 17

Описательная статистика некоторых характеристик сделок

\begin{tabular}{|c|c|c|c|c|}
\hline & Количество & $\%$ & $\begin{array}{c}\text { Средний } \\
\text { размер сделки } \\
(\$ \text { млн) } \\
\end{array}$ & Премия \\
\hline Наличные & 110 & 40,15 & 1404,40 & 29,44 \\
\hline Акции & 75 & 27,37 & 3577,94 & 37,79 \\
\hline Смешанное & 89 & 32,48 & 5015,59 & 28,09 \\
\hline Итого & 274 & 100 & & \\
\hline
\end{tabular}

Кроме того, после слияния компании, которые использовали только наличные средства или только акции при оплате, показывают сокращение волатильности, при этом при оплате акциями сокращение волатильности более значительное. Напротив, при смешанном финансировании сделки (подразумевается использование как наличных средств, так и акций) наблюдается увеличение волатильности доходности акций и значительное увеличение асимметрии. Сокращение асимметрии заметно только в слияниях, оплаченных акциями (табл. 18). 
Средство оплаты и изменение волатильности и асимметрии

\begin{tabular}{|lll|}
\hline \multicolumn{1}{|c|}{ Метод оплаты } & Изменение волатильности & Изменение асимметрии \\
\hline Наличные & $-0,00558$ & 0,018434 \\
Акции & $-0,00951$ & $-0,02029$ \\
Смешанный & 0,003452 & 0,218409 \\
\hline
\end{tabular}

Наконец, у слияний в пределах одной отрасли наблюдаются большие значения премий, чем в межотраслевых слияниях (32,67 и 28,33\% соответственно). Для обоих типов сделок наблюдается сокращение волатильности и рост асимметрии (для слияний в пределах отрасли среднее изменение волатильности $-0,0076$, в то время как среднее изменение асимметрии 0,058448, а для межотраслевых слияний - -0,00029 и 0,070819 соответственно).

\section{4. Заключение}

В данной статье мы выполнили анализ структуры капитала в контексте слияний, акцентируя внимание на трех вопросах: изменяется ли долговая нагрузка после слияния компаний; различается ли поведение покупателей в зависимости от отрасли; какова характеристика распределения доходностей и их изменение при различных слияниях, методах оплаты и премии, уплаченной за цель.

Мы внесли вклад в существующий объем литературы о структуре капитала при слияниях компаний, а также о потенциале получения синергии (финансовой, операционной и из-за комплементарности ресурсной базы), проверив ранее полученные результаты, проведя анализ в разрезе различных отраслей и предложив новые направления для будущих исследований значимости склонности менеджмента к азартному поведению при слияниях.

\section{Список литературы}

1. Agliardi, E., Amel-Zadeh, A., and Koussis, N. (2011), Optimal capital structure and growth options in M\&A, mimeo.

2. Barclay, M., Morellec, E., and Smith, C.W. (2006), On the debt capacity of growth options, Journal of Business, 79 (2006) 37-59.

3. Bradley, M. Jarrell, G. and Kim, E.H. (1984), On the existence of an optimal capital structure: theory and evidence, Journal of Finance, 39 (1984) 857-878.

4. Bruner, R.F. (1988), The Use of Excess Cash and Debt Capacity as a Motive for Merger, Journal of Financial and Quantitative Analysis, 23 (1988) 199-217.

5. Cai, J., and Zhang, Z. (2011), Leverage change, debt overhang, and stock prices, Journal of Corporate Finance 17(3) (2011) 391-402.

6. DeAngelo, H., DeAngelo, L., Whited, T.M. (2011), Capital Structure Dynamics and Transitory Debt, Journal of Financial Economics, 99 (2011) 235-261.

7. Denis, D.J., and McKeon, S.B. (2011), Debt Financing and Financial Flexibility: Evidence from Pro-active Leverage Increases. AFA 2010 Atlanta Meetings Paper. Available at SSRN: http://ssrn.com/abstract=1361171.

8. Fama, E.F., French, K.R. (2002), Testing Trade-Off and Pecking Order Predictions About Dividends and Debt, The Review of Financial Studies, 15 (2002) 1-33.

9. Frank, M.Z., and Goyal, V.K. (2003), Testing the pecking order theory of capital structure, Journal of Financial Economics, 67 (2003) 217-248.

10. Franks, J.R., Harris, R.S., and Mayer, C. (1988), Means of Payment in Takeovers: Results for the United Kingdom and the United States in Corporate Takeovers: Causes and Consequences, Editor: Alan J. Auerbach, National Bureau of Economic Research. P. 221264.

11. Galai, D., and Masulis, R.W. (1976), The option pricing model and the risk factor of stock, 
Journal of Financial Economics, 3 (1976) 53-81.

12. Ghosh, A. and Jain, P., 2000, Financial leverage changes associated with corporate mergers, Journal of Corporate Finance 6, 377-402.

13. Gugler, K., and Konrad, K.A. (2002), Merger Target Selection and Financial Structure, University of Vienna and Wissenschaftszentrum Berlin (WZB).

14. Hackbarth, D., and Mauer, D. (2011), Optimal Priority Structure, Capital Structure, and Investment, Review of Financial Studies.

15. Harford, J. (2005), What drives merger waves? Journal of Financial Economics, 77 (2005) $529-560$.

16. Harford, J., Klasa, S., and Walcott, N. (2009), Do firms have leverage targets? Evidence from acquisitions, Journal of Financial Economics, 93 (2009) 1-14.

17. Jensen, M.C. (1986), Agency Costs of Free Cash Flow, Corporate Finance, and Takeovers. The American Economic Review, 76(2) (1986) 323-329.

18. Kayhan, A., and Titman, S. (2007), Firms' histories and their capital structure, Journal of Financial Economics, 83 (2007) 1-32.

19. Kim, H.E., and McConnell, J.J. (1977), Corporate Mergers and the Co-Insurance of Corporate Debt, The Journal of Finance, 32(2) (1977) 349-365.

20. Leland, H.E. (2007), Financial synergies and the optimal scope of the firm: Implications for mergers, spinoffs, and structured finance, Journal of Finance, 62 (2007) 765-807.

21. Lewellen, W. (1971), A pure financial rationale for the conglomerate merger, Journal of Finance, 26 (1971) 521-537.

22. Makri, M., Hitt, M.A., and Lane, P.J. (2010), Complementary technologies, knowledge relatedness, and invention outcomes in high technology mergers and acquisitions, Strategic Management Journal, 31 (2010) 602-628.

23. Martin, J.D. and Sayrak, A. (2003), Corporate diversification and shareholder value: a survey of recent literature, Journal of Corporate Finance, 9 (2003) 37-57.

24. Martynova, M., and Renneboog, L. (2009), What determines the financing decision in corporate takeovers: Cost of capital, agency problems, or the means of payment?, Journal of Corporate Finance, 15(3) (2009) 290-315.

25. Modigliani, F., and Miller, M. (1958), The cost of capital, corporation finance and the theory of investment, American Economic Review, 48 (1958) 261-297.

26. Morellec, E., and Zhdanov, A. (2008), Financing and takeovers, Journal of Financial Economics, 87 (2008) 556-581.

27. Myers, S.C. (1977), Determinants of corporate borrowing, Journal of Financial Economics, 5(2) (1977) 147-175.

28. Rajan, R. G., and Zingales, L. (1995), What do we know about capital structure? Some evidence from International Data. Journal of Finance, . 50 (1995) 1421-1460.

29. Rhodes-Kropf, M., and Viswanathan, S. (2004), Market valuation and merger waves. Journal of Finance, 59 (2004) 2685-2718.

30. Rhodes-Kropf, M., Robinson, D., and Viswanathan, S. (2005), Valuation waves and merger activity: The empirical evidence, Journal of Financial Economics, 77 (2005) 561-603.

31. Schneider, C., and Spalt, O.G. (2010), Acquisitions as lotteries: Do managerial gambling attitudes influence takeover decisions? Working paper.

32. Titman, S., and Wessels, R. (1988), The determinants of capital structure, Journal of Finance, 43 (1988) 1-19.

33. Uysal, V.B. (2011), Deviation from the Target Capital Structure and Acquisition Choices, Journal of Financial Economics, 102 (2011) 602-620.

34. Yang, T.-H. (2009), The adjustment of capital structure in mergers and acquisitions: Re-visit the theory of optimal capital structure. Working paper. 